\title{
BACK TO THE BEGINNING OF THE FUTURE: COMPARING DIGITAL POLICIES OF THE NETHERLANDS AND GERMANY*
}

\author{
C. M. Feenstra \\ St. Petersburg State University, \\ 7-9, Universitetskaya nab., St. Petersburg, 199034, Russian Federation
}

The aim of this article is to compare the introduction of digital technologies in public administrations in the Netherlands and Germany. In academic research, models are developed to analyse the level of digitalization and performance of different organizations. Models serve to simplify reality in research, but the danger exists that this simplification starts to shape our understandings of different issues. In order for one to understand the current state of affairs, an understanding should be built towards the first initiatives regarding the digitalization of public administrations. Therefore, in this article, the policy notes of the Netherlands from 1995 and Germany from 2001 have been analysed and compared to determine the differences in designing and implementing digital technologies in public administrations. Different elements of the policy notes have been manually selected to offer a credible comparison of the two approaches towards digitalization. Due to the scope of this research, limited information has been provided about the influence of initiatives from the European level on the level of the Member States. The results show that both countries have a specific approach towards digitalization of public administration; the Netherlands focused on the utilization of the potential of digital technologies for her constitutional democracy. Germany, on the other hand, largely focused on developing the appropriate IT infrastructures as well as its central coordination. Finally, in the Netherlands, the government turned into a facilitator, enabling different actors to collaborate in numerous projects, with a strong focus on accessibility and inclusion. In Germany, despite the fact that the government already focused on the development and implementation of an IT infrastructure in the early 2000s, the focus is still laid on improving the digital infrastructure of the country.

Keywords: digital government policies, digitalization, public administration, comparative public policy, Germany, the Netherlands, e-Government, Industry 4.0.

\section{INTRODUCTION}

Studies and research all focus on different aspects of e-Governance; introducing models of development, definitions, technological requirements. Some focus more on the "e" than on the "government", others argue that before there can be focused on "government", there should be focused on the implementation of the electronic part. Janowski [Janowski, 2015], offered a four-stage Digital Government Evolution Model. Zahran et al. [Zahran et al., 2015], expressed the need to develop a good theoretical model for different levels of e-Government (national, local, municipal). As elaborated

* This work was supported with a grant from the Russian Science Foundation (grant no. 19-1800210 "Political ontology of digitalization: Study of institutional bases for digital forms of governability"). Supervisor of the article - prof. Dr. L. V. Smorgunov.

() Санкт-Петербургский государственный университет, 2020 
on in the research of Zahran et al. [Zahran et al., 2015], there does not exist one single and correct way introducing digital technologies in public administrations. As with other country aspects, each country develops in its own specific way, determined by the nature of that society, the political culture and structure, and more. The use of e-Government models is misleading, and there should be looked at components rather than stages in isolation. The approach that the Netherlands has taken in introducing digital technologies could be transformed into a model of how to introduce e-Government policy. However, that would not necessarily mean that it would have worked in the exact same manner in Germany. It is possible to identify the same obstacles for public administrations with regards to e-Government. Nevertheless, obstacles would occur in different patterns, since the initial approach of designing the introduction of digital technologies differs per country. The Netherlands and Germany; neighbours, strong bilateral relations, cross-border cooperation (public and private sector), both a direct style of communication, cultural "similarity". The countries have a lot in common but differ in a lot of aspects. Several lessons can be learned when looking at the digitalization of the public administrations in Germany and the Netherlands. The stereotypical image of Germany, as a correct and structured country can be found back in the first policy design for the implementation of BundOnline 2005. Germany started with a list of 355 government services which could be digitalized; how to ensure the safe use of it, establishing the formal procedures from the federal level; describing technological features, step by step. The stereotypical image of the Dutch, as sober people with an open view, can also be found back in the policy note (1995) Information Provisions Public Sector. The Netherlands was more focused on the goals and action points, with special attention paid to what information and communication technologies could potentially mean for the Dutch constitutional democracy, and the needs of different groups of society. As a Dutch person myself, by giving the following statement, I hope to offer you an insight into the Dutch political sphere, "This is the political side, our goals and plans should be understandable. We have our specialists for the technological details". This statement aims to serve as an example for the nature of politics in the Netherlands. In Germany, on the other hand, it is common to have a large focus on details, adding value to clarity, structure, order and law. In order to understand the current state of affairs regarding digitalization of public administrations, it is necessary to look at the initial policy frameworks that have been put in place in the area of digitalization. In this article, the policy designs of the Netherlands and Germany will be analysed and compared.

\section{THEORETICAL FRAMEWORK}

The term e-Government refers to the "the use of information and communication technologies, particularly the Internet, in government" [Chadwick, 2016]. Research on e-Government focuses on measurement, as well as comparison, and employs benchmarks, indicators, and frameworks [Zahranet al., 2015, p. 29]. Zahran et al. [Zahran et al., 2015], stated that there is a lack of in-depth analysis of e-Government models, and that the main focus is laid on the assessment of government performance in different areas of digitalization. 
The process by which governments have moved towards digitalisation from the late 1990s has been far from linear and the implementation is not necessarily aligned with the academic discourses [Barcevičius et al., 2019, p. 11].

In recent research on exploring Digital Government transformation in the European Union [Barcevičius et al., 2019], 477 items of literature were reviewed based on analytical narrative. This was done to determine the different dimensions of digital innovations, impacts, trends, antecedents, drivers and barriers. The reviewed models described the digital evolution to move from "simple" to more "complex" forms of e-Government. The authors stated that existing models are often outdated and fail to account for "the reality of e-Government evolution at different stages" [Barcevičius et al., 2019, p. 16]. Next to that, a large number of the reviewed literature, referred to the "transformation" of government, without defining what digital transformation entail. Furthermore, Janowski [Janowski, 2015], stated that e-Government grows towards more complexity, contextualization and specialization [Janowski, 2015, p. 221]. In addition, Janowski [Janowski, 2015], compared the concept of digital government with "evolution-like processes that lead to changes in cultures and societies" [Janowski, 2015, p. 221]. The author proposed a four-stage Digital Government Evolution Model: digitalization (technology in government); transformation (electronic government); engagement (electronic governance) and contextualization (policy-driven electronic governance) [Janowski, 2015, p. 221]. Certain characteristics belong to each stage, but what is missing is the contextualization of the political system, culture and structure of a country. Moreover, Barcevičius et al. [Barcevičius et al., 2019], offered several dichotomies of innovations transforming governments: incremental innovations vs. disruptive innovations; top-down innovations vs. bottom-up innovations [Barcevičius et al., 2019, p. 19]. Next, there is indicated that in assessing e-Government, little attention is paid to, among others, the goals of policies, consumer needs, nor to how the implementation can create public value [Barcevičius et al., 2019, p. 29]. Barcevičius et al. [Barcevičius et al., 2019], identified six factors affecting the digital government transformation: technological, organisational, legal, ethical, social / cultural, economic / financial [Barcevičius et al., 2019, p. 57]. Technological requirements are considered key in the digitalization process. The main issues in the technological aspect concern the IT infrastructure, interoperability, access to data, legal, political, social and institutional issues [Barcevičius et al., 2019, p. 57-59]. Regarding the organisational factors, key elements are strategy, human resource strategy, digital skills, managerial skills [Barcevičius et al., 2019, p. 59-60]. In the legal aspect, an appropriate legal framework should be in place. The ethical aspect concerns "citizens' trust and confidence" [Barcevičius et al., 2019, p. 61]. Little information has been provided about the social and cultural factors in the digital transformation of governments. In research of social and cultural factors, there is mainly looked at the citizen perspective on e-Government related areas. Next to that, the different levels of e-Government development between (developed and developing) countries can be better explained through cultural differences instead of economic and technological development [Barcevičius et al., 2019, p. 62]. 
What is striking about the research report of Barcevičius et al. [Barcevičius et al., 2019], is that none of the models look at the context of a country, not in terms of formal procedures, but in terms of the nature of the country. In policy sciences, a model is a representation of reality. Therefore, in this article there is proposed to bring the research of e-Government back to the original basis of policy research itself, by offering a representation of reality. The working definition of policy sciences is normally concerned with knowledge of and in the decision processes of public and civil order. The policy approach has three main attributes: contextuality, problem orientation and diversity.

The political nature of a country determines the approach which is taken towards any policy area, not only in the field of digitalization or e-Government. The political and cultural values determine the manner in which goals and action points are prioritized. Interestingly, in academic discourse in the field of e-Government, a lot of attention is paid to the technical details, as well as to determining the way in which governments are supposed to move forward. Therefore, in this article, by going through the different manually selected elements of the policy documents of the Dutch and German government, there will be demonstrated how the political cultures of the two countries influenced the course of introducing and implementing new policies at the start of the new age of the information society. There will be looked at the motivations of both countries, which will be labelled as "initiation". Next, by discussing the approaches taken by both countries, there will be demonstrated that the Dutch are practically oriented, and the German are focused on technical details. To further elaborate on the differences between the approaches, the main elements of the initiatives of Overheidsloket 2000 and BundOnline 2005 (Government service counters) will be outlined. Furthermore, there will be looked at common grounds, as governments strive for the achievement of costeffectiveness, efficiency and simplification. Moreover, there will be looked at the role of the government of both countries. Additionally, information will be given about the current state of affairs.

The main idea one should keep in mind while reading this article, as well as learning about different e-Government processes and initiatives, is that, before new policy and processes can be put in place, a window of opportunity has to open up; society has to be ready for change. One can construct the most perfect IT infrastructures and create all corresponding procedures, but if there is not anticipated on the needs of, and changes in, society, it will be more difficult to achieve success. The implementation of digital technologies goes beyond putting a digital infrastructure in place.

\section{LIMITATIONS}

Firstly, it was planned to provide information about initiatives at the level of the European Union and their influence on the domestic developments. However, due to the scope of this article, this will not be discussed. It was interesting to gain insights about the role of education and training, but it will not be included in this article. Moreover, little attention will be paid to the legal frameworks put in place, the exact 
stakeholders and division of responsibilities between different levels of government. Apart from that, in-depth information about data security and privacy will not be discussed.

\section{INITIATION}

In the Netherlands, the shift to the information society caused the government to revise her strategies and goals of public services. Citizens were no longer seen as mere receivers of government services. The new approach, as described in the policy note, in literature referred to as new public management, put the purpose and potential of government services into a new perspective; looking at citizens as customers, whose needs are to be fulfilled. In order to understand the needs of citizens as customers of government services, State Secretary of Interior Relations, J.Kohnstamm [Kohnstamm, 1995], developed the policy note "Information Provision Public Sector" (Session 1994-1995; 20 644, no. 23). The policy note stemmed from collaboration of the members of government responsible for "Action program Electronic Highways": Economic Affairs; Transport, Public Works \& Water Management; State Secretary of the Ministry of Education, Culture \& Sciences. Different initiatives already existed at different levels of government institutions, municipal, provincial, institutions. The policy note planned the make use of regular budgets, Overheidsloket 2000 was funded as part of action line 5 "Action program Electronic Highways" [Tweede Kamer, 1995, p.6].

In Germany, the implementation plan for the e-Government initiative "BundOnline 2005" was developed in the framework of modernization of public administration. In 2000, Bundeskanzler Gerard Schröder initiated BundOnline 2005. One year later, the policy implementation plan was presented and adopted by the federal government. This initiative had a clear focus on the desired outcome, timeline, budget and goal. By 2005, all federal states were expected to have offered a minimum of 355 public services online. The aim was to make government services faster, easier, and more efficient. In doing so, the satisfaction of citizens regarding politics and administrations, as well as the attractiveness of the business climate of Germany, were expected to increase. The government created a budget of 1,65 billion euros [BMI, 2001].

\section{APPROACH}

The Dutch policy note of 1995 is divided into three chapters: (1) Information society: opportunities and dilemmas for governance; (2) Communication citizen-government; (3) Behind the scenes. Lastly, a comprehensive overview of action points and planning is provided. In the appendices of the policy note, an overview is given of the most important action points announced in the note, including an elaborated plan of action for each. In 1995, the main goal for the Dutch government consisted out of two themes: relation citizen-government; effective organization of the management of government [Tweede Kamer, 1995, p. 7]. Thus, improving the relationship between citizens and government, and the increase of efficiency of government services by means of the use of information. The policy note offers a thorough de- 
scription of different sets of goals and action points. The main thought of the policy initiators concerned how there could be made use of possibilities and dilemmas of ICT in improving the functioning of the democratic constitutional state. Before goals and action points were formulated, an overview of existing and ongoing projects, and developments, within the Netherlands was given; large-scale intergovernmental projects had already been taking place. Interestingly, a separate paragraph is devoted to the cultural and societal consequences of information technologies; a brief historical analysis; an overview of potential consequences; and ways of how to anticipate on the aforementioned aspects. The societal, historical and political analysis led to the formulation of nine goals / visions. The focus was laid on (1) improvement of services, increasing citizen (2) engagement and (3) participation, (4) government transparency and accessibility, (5) prevent dichotomy of society, (6) primacy of politics, (7) securing opportunities of documented accountability, (8) collaboration and standardization of the use of information, (9) building reliable information systems [Tweede Kamer, 1995, p. 14-15]. More goals were presented in the other chapters: communication citizen-government; behind the scenes. To achieve the development of a "responsive, consistent, accessible, transparent, receptive" government, six points of action were established; Overheidsloket 2000 (Government service counter); pattern recognition in questions and complaints of citizens, as well as corresponding solutions; small-scale experiments, electronic discussions public interest; key term in government information electronically is "accessibility"; revision of privacy law in the future [Tweede Kamer, 1995, p. 5].

The approach of the German government is characterized by the central coordination of the implementation of e-Government initiatives and use of IT architectures, as well as the use of ICT to improve government services. The design of the implementation plan of BundOnline 2005 was motivated by experiences from big economic corporations, such as eBusiness-initiatives. Those initiatives offered the necessary stimuli and concrete examples of modernization of services. The existence of eBusiness provided a common goal; an implementation plan and budget for different fields of industry, as well as a common infrastructure for businesses. BundOnline 2005 should bridge the at that time existing gap between development of businesses and public administrations. To ensure the strategic development of all administrations, in addition to BundOnline 2005, a special e-Government-implementation plan was developed to support the implementation at all administrations and offer strategies for specific ministries. In order to further the modernization of public administration, the term public services should be reconceptualized into the modern sense of it. In reconceptualizing public services, the implementation plan highlights the importance of changing the strategy to quality-oriented and customer-oriented. In doing so, the government planned to determine which public services for citizens, economy, science and other public administrations, require prioritization in online services. The main focus was put on three value-adding stages: information, communication, transaction [BMI, 2001, p. 18]. In addition, value was added to efficiency, cost effectiveness and usability of online services. The improvements were mainly focused on the availability of online public services and the reorganization of processes. The implementation plan of BundOnline 2005, included: a proposal of 
which government services, between 2002-2005, should be made available online; a proposal of which technical requirements and standards should be put into place to ensure the gradual implementation; specification of financial needs and resources, with a yearly budget [BMI, 2001, p. 6]. Yearly targets were created to guarantee feasibility, to put legal frameworks into place, and the targets anticipated on available resources within the ministries and government institutions. Next to that, in the framework of the policy initiative, a dialogue was opened with modern service companies, the private sector industry. In BundOnline 2005, three categories of relations were established: Government-to-citizen (G2C); Government-to-business (G2B); Government-to-government (G2G) [BMI, 2001, p. 22]. The implementation plan offered five general points of action for development: implementation agency, one for all (OFA), competence centre, central coordination, standards and architecture for e-Government (SAGA).

\section{GOVERNMENT SERVICE COUNTERS}

Overheidsloket 2000 (government service counter) was one of the initiatives included in the policy note of the Dutch government. The communication between citizens and government consists out of two components: a relation government regarding (political) decision-making, and a relation government "customer" regarding government services [Tweede Kamer, 1995, p. 15]. Those two components relate to the following to themes: service-consistent; participation-transparent. Three projects were developed to pave the way to Overheidsloket 2000: real-estate counter; knowledge system for elderly and disabled people; "know-your-rightspillar" [Tweede Kamer, 1995, p. 19]. To achieve these goals, effective technologies were used to foster better services. It is important to go deeper into "better service". To elaborate, Kohnstamm [Kohnstamm, 1995], differentiated between citizen as customer for government services and citizen as a customer on the free market. Government services were to be improved by thinking from the citizen-perspective (customer-perspective), and most importantly, by analysing, and anticipating on, the wishes and expectations that come with the liberalization of public services [Tweede Kamer, 1995, p. 19]. This was not the first initiative; experiments had been taking place since 1992. The experiments provided practical evidence and information for making informed decisions. Next to that, the experiments led to the formulation of several questions: "what kind of tasks and competences division between the contact-point with the citizen (front office) and supporting organisations (back office) would be most adequate for realization of making the government "responsive" as a whole?"; "are there any specific educational requirements of front desk staff, how do they develop, and how do we motivate them continuously?"; "which approach would be required within the organisation, including "back office", administrative and political direction, to ensure the government "counter" to be and continue to be responsive?" [Tweede Kamer, 1995, p. 20]. The three sub-projects made up "Phase 1 " of the road to "Overheidsloket 2000". The government service counter was to be submitted as one of the projects in the framework of "line-of-action 5" under Action Program Electronic Highways [Tweede Kamer, 1995, p. 21]. At that moment 
in time, the bottom-up initiatives found common grounds of interest for the further development of initiatives.

The Dutch policy note offered detailed descriptions to justify policy decisions and steps to be taken. The implementation plan for BundOnline 2005 offers detailed information about technological steps, basic components and software to be put in place. BundOnline 2005 has been described as an important steppingstone of the politics of the federal government in developing Germany as an information society and served as an instrument to simplify structures and processes of the federal government. The plan consisted out of pilot projects for e-Government solutions, the further development of the government portal, and the development of the e-Government handbook. The introduction of electronic services goes hand in hand with the reorganization of activities of all departments. In the technical aspect, the government possessed required IT-tools and structures in supporting the implementation of e-Government. The technical feasibility of the implementation was to be realized by the deployment of basic components (data security, payment services, document management, etc.), and service-specific usages were to be determined. The applications concerned service-specific software components, which were to be distributed at local levels of government. Value was added to those components since it allowed for different services with divergent needs to employ the same IT components; increasing the efficient use of resources. Basic components ensured a standard level of development of services and was centrally planned and distributed at the state levels. The systems are central for ensuring the usability of all corresponding needs. Developing central structures was necessary to ensure the effective coordination of the initiative, as well as allowing for the exchange of know-how [BMI, 2001]. Five basic principles were put in place for the implementation of BundOnline 2005:

Table. Overview basic principles

\begin{tabular}{|l|l|}
\hline \multicolumn{1}{|c|}{ IT standards } & \multicolumn{1}{|c|}{ Building blocks } \\
\hline \multicolumn{1}{|c|}{ IT architecture } \\
\hline Interoperability and portability & Befine e-Government solutions \\
\hline $\begin{array}{l}\text { General competence centre, technical specifi- } \\
\text { cations of e-Government solutions }\end{array}$ & Exchange know-how \\
\hline $\begin{array}{l}\text { Implementation and use of applications, open- } \\
\text { ness, scalability, multi-backend skills, simplified } \\
\text { system management, remote, operating system } \\
\text { neutrality }\end{array}$ & \\
\hline Continuously operate, analyse and update & Change management processes \\
\hline
\end{tabular}

Source: [BMI, 2001] (Own translation). 


\section{COMMON GROUND: COST-EFFECTIVENESS AND EFFICIENCY}

The Dutch government established a platform with telematics and experts for the purpose of standardization the use of IT. This platform is an overarching system for the maintenance, expansion, generation of new profiles, evaluation and establishment of task forces. Moreover, research was used to find the most cost-effective way to make information digitally sustainable. In addition, new laws were to be developed to efficiently combat fraud and crime. The desired outcome for cost-effectiveness and efficiency was also reflected in the introduction of personal identification numbers for citizens, the introduction of basic register systems (GBA) for government agencies, as well as referral indices (GBI). In this manner, the amount of data gathered from citizens was reduced, and was now linked to their personal identification number. The GBA and GBI served for simplifying information exchange and the search for information between government agencies.

In Germany, the implementation plan for BundOnline 2005 was motivated by the need to make more effective use of tools to reach a certain level of efficiency. Therefore, the policy initiators developed a list of about 400 public services. The services were evaluated on user segment size, advantages, resource saving potential, strategic advantages, synergy potential. The implementation agency was established to coordinate the overall implementation. Individual states were responsible for implementation at the decentralized level. The "Einer-für-alle" principle (one for all) was put in place to avoid parallel developments and deploy qualitatively high-quality software systems within short periods of time [BMI, 2001, p.38].

\section{THE ROLE OF THE GOVERNMENT}

The Dutch government employed a bottom-up approach; gathered experiences from all different levels of governance, discussed the common issues and questions, carefully analysed the societal, cultural, economic, political and historical context, determined the needs of different groups of society. The first question a Dutch person would ask is "how does this contribute to my development and what do I get out of it?". This is exactly the approach taken by the Dutch government, by asking the question, "what is the influence of ICT on our constitutional democracy, and how can we anticipate on it?" [Tweede Kamer, 1995, p.7]. After gathering necessary information, the ownership, and responsibility of further strategic development of sub-goals were transferred to the corresponding ministry or agency. Subsequently, goals are set, evaluation procedures are developed and put into place, and in a given time period, an all-encompassing evaluation is conducted. After offering the policy note of 1995 to the parliament, municipalities could voluntarily sign up to participate in the pilot projects of Overheidsloket 2000. The scope of the policy note does not solely concern asking questions and looking at different contexts, it also included action points for internal change. The policy initiator determined eight points of action to establish a better common information-infrastructure [Tweede Kamer, 1995, p. 6]. Those points concerned: strengthening the unity of government and simplifying the common use of information (research on how to achieve streamlined deployment of 
key definitions); simplifying exchange of information within and with the government (sectoral/overarching referral indexes); privatization should take the realization of the primacy of politics into consideration; exchange of information should be transparent and cost-effective; common purchase of (data)communication facilities (Overheidsnetwerk 2000 / government network); Government information service decree (new laws and regulations); information should be reliable, available and complete (Cabinet continues with existing policy and expands scope of information security); government accountability (research on cost-effective information storage) [Tweede Kamer, 1995, p.6].

Germany carefully examined the use of technology in the government, and how to transform it, and developed an umbrella framework from the federal level to the federal states. The main thought of the policy plan BundOnline 2005 is ensuring the modernization of the government, catching up with the private sector, and strengthening the position of the country. In this aspect, the government employed a top-down approach, focused on feasibility. In Germany, feasibility can be understood as setting clear targets, having a timeline, a corresponding financial plan, and most importantly, a legal framework. In the case of BundOnline 2005, feasibility includes setting out the technical framework, requirements, and steps. In this process, the government set a clear target of minimum 355 public services to be made available by 2005 , with corresponding yearly targets and financial resources. Moreover, the government ensured the development of the technical infrastructure, requirements, standards, categorization. Next to that, central coordination and implementation agencies were established. Since the beginning, a considerable amount of attention was paid to the development of a corresponding legal framework. Data security and privacy are important elements for German society. Apart from the previously discussed responsibilities of the federal government, further IT provision of the federal administration, as well as developments and conceptualization for specific departments, are decentralized. Finally, the IT departments of ministries were responsible for developing strategies and frameworks [BMI, 2001].

\section{THE STATE OF AFFAIRS IN 2020}

Industry 4.0 refers to the fourth industrial revolution, marked by digitalization of the industrial sector. This leads to new trends and developments. Digitalization calls for new skills, knowledge, competences, job market, job descriptions, professions. In the European Union, a harmonized approach is taken to offer support to the development of all Member States. It also calls for new legislation, new strategies, business models. Jobs appear and jobs disappear, the rapid evolvement in the digital era calls for a smart strategy. EU-wide strategies and plans are developed for all aspects related to the single market and the competitiveness of the Union. Member States translate this into national policy, depending on the type of EU decision (regulations, directives, decisions, recommendations, opinions, delegated acts, implementing acts). Therefore, all Member States develop their own strategies from European to national to local levels. The main trends concern, digital single market, data security and privacy, participation, accessibility, inclusion, cohesion and education. The roles 
of the citizens and other actors are changing, not only as a result of digitalization, but also as a result of the increasing cooperation at the EU-level. The initiatives from the EU-level function as an umbrella framework for the Member States. The role of citizens is changing simultaneously, with an increase of responsibility, autonomy and "watch dog" function. Digitalization also brings uncertainty about the future jobs and knowledge, therefore, governments take initiative to incorporate digital skills and knowledge into the curriculum, not only in educational institutions, but also "on the job". This is necessary to increase and improve countries' competitiveness and resilience for the future. Apart from that, the role of civil society is increasing, local initiatives come into being for different societal purposes, taking upon roles which previously might have been a responsibility of government institutions. Lastly, a large number of cross-border initiatives exist in Europe, to exchange knowledge and initiate collaboration across the EU (in different sectors). The European Digital Industry Alliance (DIA) brings together six industrial clusters (over 800 companies) to explore the challenges and opportunities of Industry 4.0, developing ICT and clusters to support companies in modernizing production, business models [DIA, n. d.].

The Netherlands is one of the top countries in the EU when it comes to digitalization. In general, Dutch society has an innovative character and is open for change. The business industry in the Netherlands is highly digitalized. Special attention is paid to lifelong learning, offering and ensuring that society has all necessary skills for different purposes. Accessibility and inclusion are key to make sure that "everyone can participate" in all aspects of life. The digital era enhances the possibilities for citizen engagement in the decision-making processes of the government, increases the watch dog function of citizens, and participation and initiatives of civil society. Citizens have more autonomy in controlling personal data and receiving information about how the data is used and by who. Data security and privacy are important in the field of cyber criminality. The government becomes a facilitator to stimulate citizens, enterprises, educational institutions, scientists, to collaborate in different types of projects. Projects are called Proeftuin Lokale Digitale Democratie (testing ground local digital democracy), field labs / hubs, Start-ups in Residence, Digicampus [EZK, 2019].

Germany falls behind numerous countries, this has mainly to do with the fact that internet network is not equally developed in all federal states of Germany. The most important element connected to digitalization is data protection and security, this is related to the German culture. Germans generally support the further digitalization of society but are sceptical about the use of digital technologies. Germany scores good on average, but when it comes to e-participation, there is room for a lot of improvement. Before it is possible to focus on this aspect, the digital infrastructure needs to be improved. The government prioritizes lifelong learning, to ensure that society possesses all necessary skills and knowledge to make use of digital technologies for different aspects of life. German society is old fashioned in their bureaucratic processes and slowly adapting to change. Most SMEs do not have a strategy for Industry 4.0, and about fifty percent of larger enterprises has a strategy in place. The issue here is that people are sceptical towards change, add great value to data security and privacy, have insufficient digital talent and capacity, digital 
competences of employees lag behind. At the same time, the government expands laws and regulations concerning the social market economy to a "digital social market economy".

\section{DISCUSSION}

In the work of Barcevičius et al. [Barcevičius et al., 2019], there has been explained that little attention is paid to the goals of Digital Government Policies as well as the potential to create public value in the implementation of digital policies. Therefore, it is interesting to conclude that in the policy note of the Netherlands, most paragraphs are dedicated to goal formulation and discovering how these goals can create public value. The initiation in the Netherlands can be characterized by anticipation on the development of an information society, and the new customer-oriented approach introduced by new public management. In Germany, the initiative was developed as part of the modernization strategy of the government. As well as the goal to increase the level of satisfaction of all relevant actors and increase the attractiveness of the business climate.

As discussed in the theoretical framework, there are six factors influencing digital transformation: technological, organisational, legal, ethical, social / cultural, economic / financial [Barcevičius et al., 2019]. The approach of the Dutch government can be characterized by the high level of citizen-orientation, utilization of the potential of ICT for the democratic constitutional state. The main characteristics of the Dutch approach are goal setting, action points, context analysis, service improvement, citizen engagement and participation, transparency, accessibility, target-group oriented, research based, decentralization. Other characteristics concern legal frameworks, ethics. The approach of the German government is characterized by central coordination and strategic planning. The main characteristics for the German approach are central coordination, strategic planning, requirements and standards, information, communication, transaction, legal frameworks, economic / financial. Overheidsloket 2000 was driven by citizen orientation, research, cross-departmental collaboration, practice based. BundOnline 2005 revolved around putting the appropriate IT infrastructures, requirements and standards into place.

The countries have common ground when it comes to cost-effectiveness and efficiency. But also, in this aspect, the motivations behind the decisions differ. In the Netherlands corresponding analysis and research was conducted for the development of overarching systems, digital sustainability of information, legal frameworks. As well as the simplification of already existing data by introducing personal identification numbers, developing basic register systems for the government and referral indices to simplify information exchange between government agencies. In Germany, the government also aimed for the cost-effective and efficient use of resources. The aim of BundOnline 2005 is more technologically oriented; efficient use of IT and software. In this policy document, cost-effectiveness refers to the development and use of IT structures, software and procedures. Both countries have a decentralized structure of government, and also indicated that the responsibility for implementation of e-Government initiatives lays at decentralized levels of government. However, there 
is a difference between what both countries understand as the responsibility of decentralized levels of government. Now, combining the results of this research with the research of Barcevičius et al. [Barcevičius et al., 2019], several conclusions can be made. The design of the Netherlands is characterized by bottom-up innovations and incremental innovations. In 1995, experiments and digital innovations had already been taken place at different levels of government (central and decentral). Therefore, the policy note focused on the exchange of experience and existing techniques and started initiating incremental innovations together with a wide range of stakeholders. The design of Germany is characterized by top-down and disruptive innovations. The results of this article clearly demonstrate that the main focus of BundOnline 2005 was setting the standard at the federal level and to distribute it to the federal states. Subsequently, the federal states, ministries, departments were responsible in developing sector specific strategies. In the implementation plan of BundOnline 2005, information is provided about responsible ministries, only little information is provided about the role of different federal states in this process of change.

Now it has become visible how the countries differ in initial approaches in the first phases of digitalization. At the time of development as well as the following years, the role of the EU increased significantly, since digitalization offers great opportunities for improving Europe's competitiveness and strengthening the (digital) single market. The rise of EU initiatives impacts the (digital) development of Member States. However, based on the nature of a Member State, priorities can differ. The Netherlands is active and competitive, attention is paid to turning uncertainties and threats into opportunities and points of improvement, accessibility and inclusion. The Netherlands started experimenting with digital democracy through different societal projects. In Germany, the main focus is still laid on the improvement of the digital infrastructure. The unequal development of internet networks throughout the country negatively impact the overall performance of the country. The federal government prioritizes digital skills and education policy in the framework of digital policy. Data security and privacy lay at the core of digitalization in Germany.

\section{CONCLUSION}

The aim of this article was to compare the policy designs of the Netherlands and Germany in the area of digital technologies in public administrations. The decision was made to focus on specific elements of the policy documents. There was looked at initiation, approach, government service counter initiatives, the role of the government. Not enough words have been used to substantiate the cultural differences in the perspectives on the exact same manner. Efficiency is something completely different in the eyes of a German or a Dutch person. This does not mean that one is right and the other is not, it means that in research some elements of intercultural sensitivity should be incorporated when looking at different systems.

It is necessary to put everything into perspective and refer to one last source which was not discussed in this article. Fortunately, research conducted for the Directorate-General Networks, Content \& Technology of the European Commission [European Commission..., 2019], does incorporate intercultural sensitivity. The report 
on the development of e-Government of EU Member States takes the expectations of citizens into consideration when drawing final conclusions about the current state of affairs of a specific country. One example based on that report; just because Germany scores low on e-Government indicators, it does not mean that the citizens are not satisfied with the services provided by the government, it meets citizens' needs and expectations.

The kick-off of introducing digital technologies in public administrations was far from finalized. In 1996, party member of PvdA (NL) stated,

The digital memory of the government suffers from Alzheimer: once the memory gets erased, it will never return. The danger of a government with dementia is not unimaginative. The problems around hardware, software, document management are not minor, and should not be underestimated. The developments on the digital terrain are lightning fast and are catching up with the current state of affairs [Tweede Kamer, 1996, p. 1].

\section{References}

Barcevičius E., Cibaitè G., Codagnone C., Gineikytė V., Klimavičiūtè L., Liva G., Matulevič L., Vanini I. European Commission, Joint Research Centre. Exploring Digital Government Transformation in the EU, ed. by Gianluca Misuraca. Luxembourg, Publications Office of the European Union, 2019. https://doi.org/10.2760/17207.

BMI (Federal Ministry of the Interior, Building and Community). Umsetzungsplan für die eGovernment-initiative BundOnline 2005 (Stabstelle Moderner Staat-Moderne Verwaltung). Berlin, Bundesministerium des Inneren (BMI), 2001.

BMWi (Federal Ministry for Economic Affairs and Energy), n. d. "Digital Agenda". BMWi. Available at: https://www.bmwi.de/Redaktion/EN/Artikel/Digital-World/digital-agenda.html (accessed: 18.04.2020).

BMWi (Federal Ministry for Economic Affairs and Energy). White Paper Digital Platforms. Berlin, BMWi, June, 2017. Available at: https://www.bmwi.de/Redaktion/EN/Publikationen/white-paper. pdf?_blob=publicationFile\&v=2 (accessed: 06.05.2020).

BZK (Ministry of Interior and Kingdom Relations). "Digitale overheid op goed peil". Rijksoverheid, 2016. Available at: https://www.rijksoverheid.nl/onderwerpen/digitale-overheid/nieuws/2016/10/12/digitale-overheid-op-goed-peil (accessed: 06.05.2020).

Chadwick A. "E-government | political science". Britannica, 2016. Available at: https://www. britannica.com/topic/e-government (accessed: 15.04.2020).

Digital Industry Alliance, n. d. "About us". Digital Industry Alliance. Available at: https://digitalindustryalliance.eu/about-us/ (accessed: 10.05.2020).

European Commission, \& Directorate-General of Communications Networks, Content and Technology. eGovernment Benchmark 2019 country factsheets. Luxembourg, Publications Office of the European Union, 2019. https://doi.org/10.2759/641548.

EZK (Ministry of Economic Affairs and Climate Policy). Nederlandse digitaliseringsstrategie 2.0 (122042). EZK, 2019. Available at: https://www.rijksoverheid.nl/documenten/rapporten/2019/07/05/nederlandse-digitaliseringsstrategie-2.0 (accessed: 06.05.2020).

Janowski T. "Digital government evolution: From transformation to contextualization". Government Information Quarterly, 2015, vol. 32 (3), pp. 221-236. https://doi.org/10.1016/j. giq.2015.07.001.

PwC. Die vernetzte Verwaltung: Digitalisierung aus der Bürgerperspektive. Germany, PricewaterhouseCoopers, 2017.

Schröder C. Herausforderungen von Industrie 4.0 für den Mittelstand. Bonn, Friedrich Ebert Stiftung, 2016. Available at: http://library.fes.de/pdf-files/wiso/12277.pdf (accessed: 08.05.2020). 
Tweede Kamer (The House of Representatives). J. Kohnstamm (BZK). Information services publicsector. Kamerstuk 20644 | nr. 23, nota. Tweede Kamer der Staten-Generaal. 1995. Available at: https://zoek.officielebekendmakingen.nl/kst-20644-23.html (accessed: 18.04.2020).

Tweede Kamer (The House of Representatives). Report of general consultations (Information services public sector). Kamerstuk 20644 | nr. 26. Tweede Kamer der Staten-Generaal. 1996. Available at: https://zoek.officielebekendmakingen.nl/kst-20644-26.html (accessed: 18.04.2020).

Zahran I., Al-Nuaim H., Rutter M., Benyon D. A Critical Analysis of E-Government Evaluation Models at National and Local Municipal Levels. The Electronic Journal of E-Government, 2015, vol. 13 (1), pp. 28-42. Available at: http://www.ejeg.com/issue/download.html?idArticle=419 (accessed: 01.05.2020).

Christina Maria Feenstra - Student; kingafeenstra@gmail.com

Received: August 7, 2020

Accepted: August 21, 2020

For citation: Feenstra C.M. Back to the beginning of the future: Comparing digital policies of the Netherlands and Germany. Political Expertise: POLITEX, 2020, vol. 16, no. 3, pp. 360-374. https://doi.org/10.21638/spbu23.2020.304 (In Russian) 